\title{
Temperature-Controlled Encapsulation and Release of an Active Enzyme in the Cavity of a Self-Assembled DNA Nanocage
}

\author{
Sissel Juul, ${ }^{\dagger}$ Federico lacovelli, ${ }^{\ddagger}$ Mattia Falconi, ${ }^{\ddagger}$ Sofie L. Kragh, ${ }^{\S}$ Brian Christensen, ${ }^{\perp}$ Rikke Frøhlich, $^{\perp}$ \\ Oskar Franch, ${ }^{\perp}$ Emil L. Kristoffersen, ${ }^{\perp}$ Magnus Stougaard, ${ }^{\|}$Kam W. Leong, ${ }^{\dagger}$ Yi-Ping Ho, $^{\S}$ Esben S. Sørensen, ${ }^{\perp}$ \\ Victoria Birkedal, ${ }^{\S}$ Alessandro Desideri, ${ }^{\ddagger}$ and Birgitta R. Knudsen ${ }^{\S, \perp, *}$ \\ ${ }^{\dagger}$ Department of Biomedical Engineering, Duke University, Durham, North Carolina 27708, United States, ${ }^{\ddagger}$ Department of Biology, University of Rome "Tor Vergata", \\ Rome 00133, Italy, ${ }^{\S}$ Interdisciplinary Nanoscience Center (iNAN0), Aarhus University, Aarhus 8000, Denmark, ${ }^{\perp}$ Department of Molecular Biology and Genetics, \\ Aarhus University, Aarhus 8000, Denmark, and "Department of Pathology, Aarhus University Hospital, Aarhus 8000, Denmark
}

\begin{abstract}
We demonstrate temperature-controlled encapsulation and release of the enzyme horseradish peroxidase using a preassembled and covalently closed three-dimensional DNA cage structure as a controllable encapsulation device. The utilized cage structure was covalently closed and composed of 12 double-stranded B-DNA helices that constituted the edges of the structure. The double stranded helices

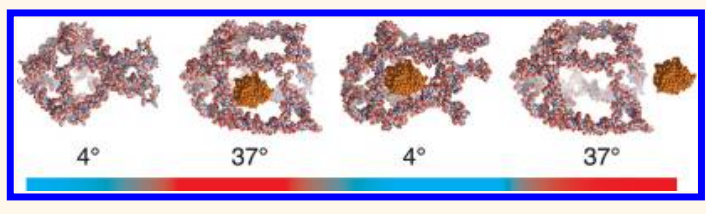
were interrupted by short single-stranded thymidine linkers constituting the cage corners except for one, which was composed by four 32 nucleotide long stretches of DNA with a sequence that allowed them to fold into hairpin structures. As demonstrated by gel-electrophoretic and fluorophore-quenching experiments this design imposed a temperature-controlled conformational transition capability to the structure, which allowed entrance or release of an enzyme cargo at $37^{\circ} \mathrm{C}$ while ensuring retainment of the cargo in the central cavity of the cage at $4{ }^{\circ} \mathrm{C}$. The entrapped enzyme was catalytically active inside the DNA cage and was able to convert substrate molecules penetrating the apertures in the DNA lattice that surrounded the central cavity of the cage.
\end{abstract}

KEYWORDS: DNA nanocage $\cdot$ controlled encapsulation and release $\cdot$ drug delivery $\cdot$ temperature $\cdot \mathrm{MD}$ simulation . fluorescence-quenching $\cdot$ self-assembly

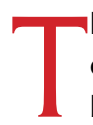
he unique self-recognition properties of DNA, its high thermodynamic stability, and the ease by which it can be synthesized have in combination made this molecule one of the most efficient building blocks for the creation of predesigned selfassembling nanostructures. Consequently a large variety of precisely programmed two- or three-dimensional (2D or 3D) DNA nanostructures have been presented during the past decade. ${ }^{1,2}$

With the increased knowledge in the use of DNA to direct assembly and functionality of nanostructures possible applications in biology are beginning to emerge. The original idea proposed by Seeman to use DNA structures as a scaffold to facilitate structural analyses of biomolecules ${ }^{3}$ is coming true with the utilization of $2 \mathrm{D}$ scaffolds to facilitate protein structure determination by cryo-electron microscopy ${ }^{4,5}$ and with the demonstration of self-assembling DNA crystals. $^{6-8}$ Moreover, 2D DNA origamis have been used as programmable and highresolution templates for the exposure and investigation of single biomolecules. ${ }^{9-13}$ For the 3D cage- or box-like structures some of the intriguing potential applications are controlled encapsulation and/or release of biomolecules for drug delivery, construction of precisely positioned bioreaction centers for single molecule detection, protection of biomolecules in hostile environments, study of intermolecular interaction or other biomedical purposes.

During the past decade an impressive variety of DNA cage structures including tetrahedra, ${ }^{14-17}$ cubes, ${ }^{18,19}$ octahedra and truncated octahedra, ${ }^{20-24}$ trigonal bipyramids, ${ }^{25}$ dodecahedra, ${ }^{17}$ icosahedra and truncated icosahedra ${ }^{10,17,26}$ as well as hybrid structures with synthetic linkers ${ }^{11-13}$ and large DNA origami based structures ${ }^{27-30}$ have been presented. Some of these structures * Address correspondence to
brk@mb.au.dk.

Received for review June 17, 2013 and accepted October 29, 2013.

Published online 10.1021/nn4030543

(c) XXXX American Chemical Society 
have been designed to change configuration in response to binding of signal molecules, which poses the possibilities of releasing or exposing a potential cargo. Such features are exemplified by an origami based DNA box presented by the Kjems and Gothelf laboratories, ${ }^{27}$ a cleverly designed origami barrel presented by the Church group, ${ }^{31}$ a switchable tretrahedra presented by Turberfield and co-workers, ${ }^{32}$ and most recently a DNA icosahedron that split in two halves upon cdGMP binding presented by Krishnan and collaborators. ${ }^{33}$ 3D DNA structures may be innate resistant to degradation in a biological environment as demonstrated by the resistance toward nuclease treatment of a covalently closed octahedral cage previously presented by our group ${ }^{20}$ and the very extensive $(42 \mathrm{~h})$ decay time of tetrahedra in $10 \%$ fetal bovine serum. ${ }^{34}$ More recently DNA origami nanoarrays were demonstrated stable in cell lysates. ${ }^{35}$ DNA cage structures have also been demonstrated capable of entering live mammalian cells, ${ }^{36}$ while DNA tubes or barrels have been demonstrated directable to specific cell types to which they can either deliver ${ }^{37}$ or expose ${ }^{31}$ their specific cargo.

Most examples of encapsulation of cargo in 3D DNA nanocages rely on covalent or noncovalent attachment mechanisms such as the entrapment of Cytochrome $C$ in a DNA tetrahedra facilitated by conjugation to one of the DNA strands constituting the cage, ${ }^{38}$ or loading of DNA conjugated protein moieties or gold nanoparticles on an origami based barrel or cage, respectively. ${ }^{31,39}$ Peptide nucleic acid (PNA) has also been demonstrated to direct peptides to the inside of a tetrahedron. ${ }^{40}$ More recently encapsulation of a single transcription factor protein inside a tetrahedron was achieved by introducing a consensus sequence on one edge of the tetrahedron to facilitate specific binding of the transcription factor. ${ }^{41}$ This procedure allowed release of the entrapped protein by nuclease degradation of the DNA cage. Until now the only examples of encapsulation without any form of attachment of the cargo have been presented by Krishnan and co-workers, who demonstrated encapsulation of gold nanoparticles ${ }^{42}$ or a fluorescent biopolymer (FD10) ${ }^{33}$ in an icosahedral using a modular assembly strategy. After assembly, cargo release was obtained by splitting the structure into the modules by which it was built. ${ }^{33}$

In the present study we demonstrate controlled encapsulation and release of the enzymatic protein horseradish peroxidase (HRP) in a DNA cage facilitated by temperature provoked "opening" and "closing" of the cage structure. This is to our knowledge the first example of controlled encapsulation and release of a protein cargo in a fully preassembled DNA nanostructure, which is not facilitated by any form of covalent or noncovalent attachment of the cargo to the DNA structure. This was accomplished by a modification to our previously published DNA cage design. ${ }^{20,21}$ In this structure eight oligonucleotides of equal length hybridize to form a truncated octahedron. According to SAXS analysis ${ }^{20,21}$ the inner cavity of the presented design has a diameter of approximately $10-12 \mathrm{~nm}$, which is large enough to accommodate the dimensions of HRP. ${ }^{43}$ This cavity is surrounded by a lattice of which the largest apertures have a diameter of $5.5-6.5 \mathrm{~nm},{ }^{20,21}$ which is small enough to prevent diffusion of encapsulated HRP. ${ }^{43}$ The original DNA cage design is composed of 12 B-DNA helices constituting the edges of the structure interrupted by short singlestranded linkers composing the six "corners" of the structure. By substituting each of the four short singlestranded linker regions in one of the cage corners with $32 \mathrm{nt}$ hairpin-forming sequences, sufficient flexibility was imposed in the structure, denoted Cage $_{h p}$ in the following, to facilitated temperature-dependent encapsulation and release of HRP.

\section{RESULTS AND DISCUSSION}

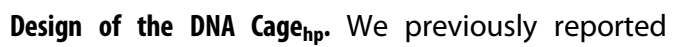
the design and assembly of DNA Cage(3T), Cage(4T), Cage(5T), Cage(6T), and Cage(7T). These structures were composed of eight oligonucleotides, which upon annealing and ligation formed a covalently closed truncated octahedron with 12 edges of each 18 base pairs B-DNA interrupted by single-stranded regions of $3,4,5,6$, or 7 thymidines, constituting the six corners of the structures. ${ }^{20,21}$ They all assembled in a one step procedure with a fairly high efficiency of around $30 \%$. As revealed by SAXS analyses they had an inner diameter varying from approximately $10 \mathrm{~nm}$ for the smallest (Cage(3T)) to $12 \mathrm{~nm}$ for the largest structure (Cage(7T)), while the maximum extension of the hexagonal faces (e.g., the apertures of the lattice surrounding the cage cavity) ranged from 5.5 to $6.5 \mathrm{~nm}$ going from Cage(3T) to Cage(7T). ${ }^{20,21}$ The dimension of the central cavity suggested that all the investigated cages would be able to accommodate the enzyme HRP (dimensions of approximately $4.5 \times 5 \times 6.5 \mathrm{~nm})^{43}$ in their center. However, Cage(3T) was chosen as the basic structure for a hairpin modified cage, in order to minimize the risk of diffusion of HRP through the lattice of the cage, since the dimensions of the hexagonal faces of Cage(3T) was demonstrated to be slightly smaller than those of Cage(4T)-Cage(7T). To induce sufficient flexibility of the basic cage design to allow for temperature-controlled encapsulation of HRP after assembly and covalent closure, each of the four short thymidine linker regions constituting one corner of the structure was replaced by a $32 \mathrm{nt}$ palindromic sequence folding back onto itself to form a hairpin structure. The anticipated structure of a cage having one corner modified with the hairpin-forming sequences while the other corners are constituted by three-thymidines linkers (denoted $\mathrm{Cage}_{\mathrm{hp}}(3 \mathrm{~T})$ in 


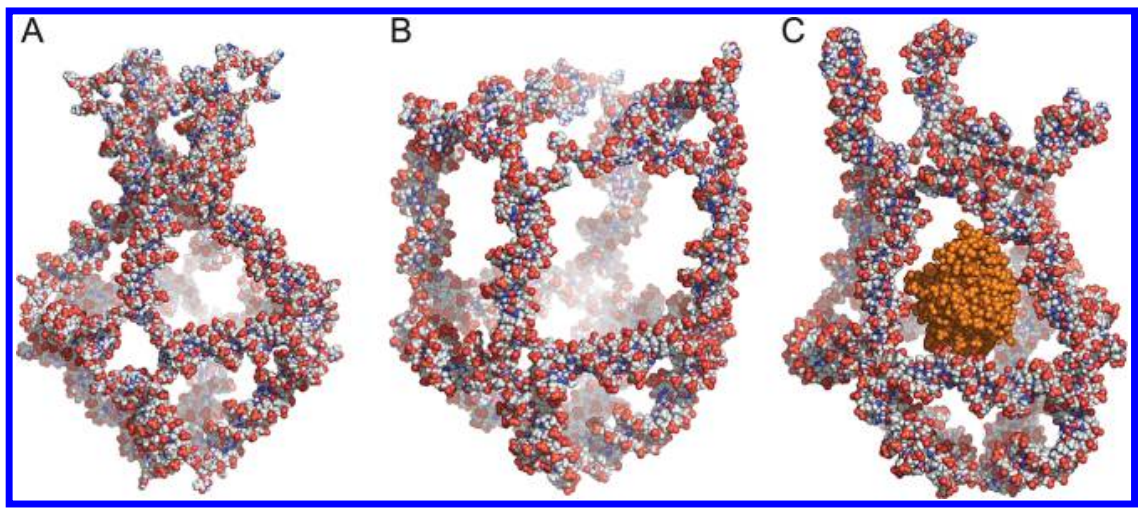

Figure 1. Atomistic models of Cage $\mathrm{hp}_{\mathrm{h}}(3 \mathrm{~T})$. (A) Closed Cage $\mathrm{hp}(3 \mathrm{~T})$ at $4{ }^{\circ} \mathrm{C}(277 \mathrm{~K})$. (B) Supposed complete extension of Cage $\mathrm{hp}_{\mathrm{hp}}(3 \mathrm{~T})$ at $37{ }^{\circ} \mathrm{C}(313 \mathrm{~K})$. (C) Closed Cage $\mathrm{hp}(3 \mathrm{~T})$ at $4{ }^{\circ} \mathrm{C}(277 \mathrm{~K})$ with HRP encapsulated.

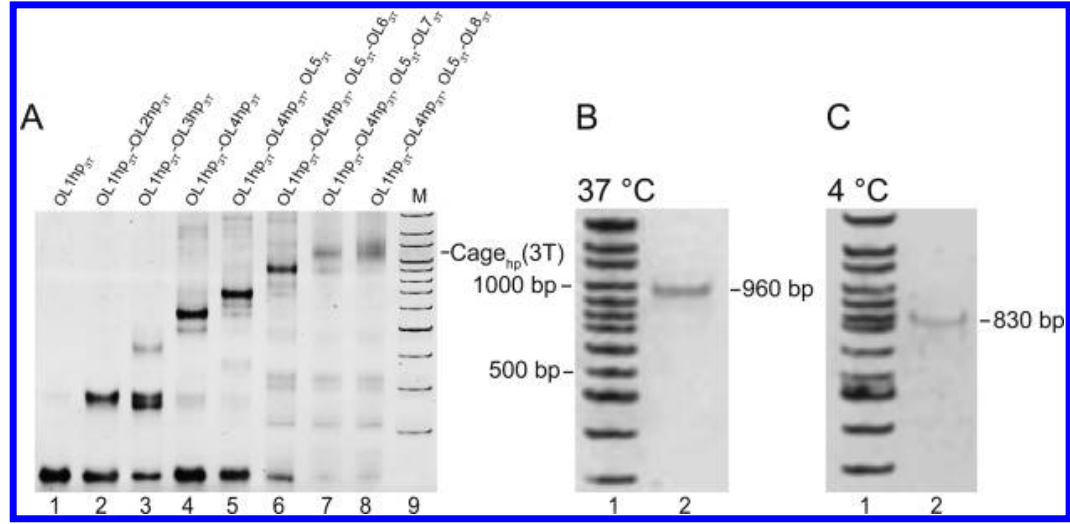

Figure 2. Gel-electrophoretic analyses of the DNA Cage $\mathrm{hp}_{\mathrm{p}}(3 \mathrm{~T})$. (A) Shows the result of a ladder experiment where increasing numbers of the DNA oligonucleotides that form $\mathrm{Cage}_{\mathrm{hp}}(\mathrm{3T})$ were annealed and ligated before gel-analysis. Lane 1 contains a DNA marker (M). Lanes 2-9 show the results of subjecting assembly reactions containing $\mathrm{OL}_{1 \mathrm{hp}}$; $\mathrm{OL} \mathrm{hh} \mathrm{P}_{3 \mathrm{~T}} \operatorname{and~OL2~} 2 \mathrm{hp}_{3 \mathrm{~T}}$;

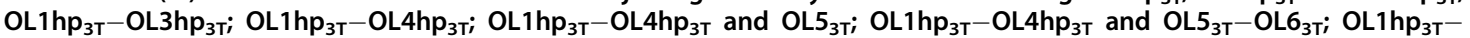
$\mathrm{OL}_{4 p_{3 \mathrm{~T}}}$ and $\mathrm{OL5}_{3 \mathrm{~T}}-\mathrm{OL7}_{3 \mathrm{~T}} ; \mathrm{OL}_{1 \mathrm{hp}}{ }_{3 \mathrm{~T}}-\mathrm{OL}_{4} \mathrm{hp}_{3 \mathrm{~T}}$ and $\mathrm{OL} 5_{3 \mathrm{~T}}-\mathrm{OL} 8_{3 \mathrm{~T}}$ to analysis in a native polyacrylamide gel. (B) Gel-analysis of purified $\mathrm{Cage}_{\mathrm{hp}}(3 \mathrm{~T})$ at $37^{\circ} \mathrm{C}$. Lane 1 contains a DNA marker (M). Lane 2 contains assembled Cage $\mathrm{hp}(3 \mathrm{~T})$ after gel-purification and preincubation at $37^{\circ} \mathrm{C}$. Compared to the marker, $\mathrm{Cage}_{\mathrm{hp}}$ (3T) has a gel-electrophoretic mobility corresponding to a $960 \mathrm{bp}$ DNA fragment (indicated to the right) at these conditions. (C) Gel-analysis of purified Cage ${ }_{h p}(3 T)$ at $4{ }^{\circ} \mathrm{C}$. Lane 1 contains a DNA marker (M). Lane 2 contains assembled Cage $\mathrm{hp}_{\mathrm{p}}(3 \mathrm{~T})$ after gel-purification and preincubation at $4{ }^{\circ} \mathrm{C}$. At these conditions the $\mathrm{Cage}_{\mathrm{hp}}(3 \mathrm{~T})$ has a gel-electrophoretic mobility corresponding to a $830 \mathrm{bp}$ DNA fragment (indicated to the right). The DNA products were visualized by EtBr staining subsequent to gel-electrophoresis.

following) is shown in Figure 1. On the basis of the annealing temperature $\left(22^{\circ} \mathrm{C}\right)$ of the utilized hairpinforming sequences, $\operatorname{Cage}_{\mathrm{hp}}(3 \mathrm{~T})$ was anticipated to attain a fully closed conformation at $4{ }^{\circ} \mathrm{C}$ (Figure 1A) and a more open conformation at $37{ }^{\circ} \mathrm{C}$ (Figure 1B). Hence, encapsulation of HRP in the cage structure (Figure 1C) was expected facilitated by heating the cage to $37^{\circ} \mathrm{C}$ in the presence of large molar excess of the protein, followed by cooling to $4{ }^{\circ} \mathrm{C}$.

Assembly and Gel-Electrophoretic Analyses of DNA Cage $_{\text {hp }}$ (3T). Covalently closed Cage $\mathrm{hp}_{\text {(3T) }}$ was assembled as described previously for Cage(3T). ${ }^{20,21}$ The specific assembly of the cage was tested by analyzing the products obtained when annealing and ligating increasing numbers of equimolar amounts of $5^{\prime}$-phosphorylated oligonucleotides added one-by-one in successive

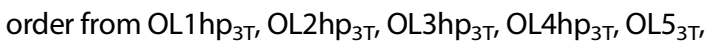
$\mathrm{OL}_{3 \mathrm{~T}}, \mathrm{OL} 7_{3 \mathrm{~T}}$, and $\mathrm{OL} 8_{3 \mathrm{~T}}$ in a native polyacrylamide gel. As evident from Figure $2 \mathrm{~A}$ the addition of increasing numbers of oligonucleotides to the assembly reaction resulted in products with decreasing gel-electrophoretic mobility essentially as it was observed previously for the assembly of Cage(3T)-Cage(7T). ${ }^{21}$ This is consistent with specific assembly of $\mathrm{Cage}_{\mathrm{hp}}(3 \mathrm{~T})$. Moreover, the fully assembled product shown in lane 8 was resistant toward boiling, exonuclease digestion and denaturing gelelectrophoresis (data not shown), suggesting that this product represents a fully and correctly assembled covalently closed cage structure. By quantification of the band representing fully assembled Cage $_{\mathrm{hp}}$ (3T) relative to the higher and lower-mobility products the yield of the correctly assembled Cage $_{h p}(3 T)$ was estimated to approximately $30-40 \%$, which is comparable to the yield previously reported for Cage(3T)Cage(7T) ${ }^{20,21}$ The anticipated yield of a DNA nanostructure was previously demonstrated to correlate to the number of double-stranded helices in the structure with a decrease in yield as the number of duplexes increase. ${ }^{44}$ Factors hampering yield are slight variations in DNA strand concentrations and potential topological 
constraint in the structures. The yield of $\mathrm{Cage}_{\mathrm{hp}}(3 \mathrm{~T})$ is approximately half the yield anticipated for a simple and highly flexible 2D structure with a similar number (12) of double helices, which most probably can be ascribed the topological constraint in the 3D cage structure. ${ }^{21}$

To investigate if $\mathrm{Cage}_{\mathrm{hp}}(\mathrm{3T})$ could undergo a temperature-dependent conformational shift, the structure was gel-purified as described previously, ${ }^{20}$ and the mobility analyzed in native polyacrylamide gels at 4 and $37^{\circ} \mathrm{C}$, respectively. As evident from Figure $2 \mathrm{~B}$ and $C$, the estimated gel-electrophoretic mobility of $\mathrm{Cage}_{\mathrm{hp}}(3 \mathrm{~T})$ corresponded to approximately the mobility of a 960 base pair DNA fragment when gelelectrophoresis was performed at $37{ }^{\circ} \mathrm{C}$ (lane 2, Figure 2B). Gel-electrophoresis at $4{ }^{\circ} \mathrm{C}$ resulted in a mobility of $\mathrm{Cage}_{\mathrm{hp}}(\mathrm{3T})$ corresponding approximately to the mobility of an 830 base pair DNA fragment (lane 2, Figure 2C). The increased mobility of $\operatorname{Cage}_{h p}(3 \mathrm{~T})$ at $4{ }^{\circ} \mathrm{C}$ relative to $37^{\circ} \mathrm{C}$ suggests that the cage was able to undergo a temperature-controlled conformational change attaining a more closed structure at low temperature and a more open structure at higher temperature. This was further supported by quenching experiments using a $\mathrm{Cage}_{\mathrm{hp}}(3 \mathrm{~T})$ variant with a fluorophore-quencher pair inserted in one of the hairpin-forming DNA strands. In these experiments, changes in fluorescence as a function of temperature and upon addition of the hairpin complementary strand suggested that the hairpins acted as a conformational switch when conditions were changed from low to high temperature (see Supporting Information Figure S1).

Temperature-Controlled Encapsulation of HRP in Cage $_{\mathrm{hp}^{-}}$ (3T). To investigate if the temperature-controlled conformational transition of $\mathrm{Cage}_{\mathrm{hp}}$ (3T) from a more open (at $37^{\circ} \mathrm{C}$ ) to a closed (at $4{ }^{\circ} \mathrm{C}$ ) structure would support the encapsulation of HRP, gel-purified $\mathrm{Cage}_{\mathrm{hp}}$ (3T) was incubated with 25 times molar excess of HRP at $37^{\circ} \mathrm{C}$ and slowly cooled to $4{ }^{\circ} \mathrm{C}$ to allow correct annealing of the hairpin structures of the cage. As negative controls, the $\mathrm{Cage}_{\mathrm{hp}}(3 \mathrm{~T})$ was subjected to similar temperature changes in the absence of added HRP or incubated with a 25 times molar excess of HRP at a constant temperature of $4{ }^{\circ} \mathrm{C}$, which was anticipated to prevent access of HRP to the central cavity of $\mathrm{Cage}_{\mathrm{hp}}(3 \mathrm{~T})$.

After incubation as described above, the generated products were separated in a native polyacrylamide gel at $4{ }^{\circ} \mathrm{C}$. The DNA cage samples with or without HRP were visualized by ethidium bromide $(\mathrm{EtBr})$ staining (Figure $3 \mathrm{~A}$ ) and cut out of the gel. The resulting gel pieces were then moved, each to their individual Eppendorf tube placed on top of an X-ray film before addition of enhanced chemiluminescence $(E C L)$, which acts as a substrate for HRP (HRP catalyzes oxidation of $E C L$ leading to light emission, which then exposes the $X$-ray film). ECL and its oxidized product are both small enough to pass in and out of the cage through the apertures in the lattice surrounding the central cavity, which was anticipated to hold HRP. Hence, in this experimental setup the presence of HRP would be detectable by a spot-shaped exposure of the film (see schematic outline of the assay in the lower panel of Figure $3 \mathrm{~A}$ ). As evident from the HRP activity spot test shown in Figure 3B, no HRP activity was detected in the purified Cage $_{h p}(3 T)$ sample incubated in the absence of HRP (sample 1). A substantial amount of HRP activity was detected in the $\operatorname{Cage}_{\mathrm{hp}}$ (3T) sample subjected to a temperature shift from 37 to $4{ }^{\circ} \mathrm{C}$ in the presence of molar excess of HRP (sample 2), while considerably less HRP activity was observed in the $\operatorname{Cage}_{h p}(3 T)$ sample incubated with HRP at a constant temperature of $4{ }^{\circ} \mathrm{C}$ (sample 3) (for quantitative comparison see Figure $3 \mathrm{D}$ ). This suggests that increasing the temperature to $37{ }^{\circ} \mathrm{C}$ induced a sufficiently open or flexible structure of $\mathrm{Cage}_{\mathrm{hp}}(3 \mathrm{~T})$ to allow entrance of HRP, while shifting the temperature to $4{ }^{\circ} \mathrm{C}$ induced a sufficiently closed conformation to retain the encapsulated HRP even under the forces subjected to the cage during gel-electrophoresis. A low level of background HRP activity was observed in sample 3 containing Cage $_{\text {hp }}(3 T)$ that was incubated with HRP at a constant temperature of $4^{\circ} \mathrm{C}$. Since all cage structures used in the current study were exonuclease digested and gelpurified, this background activity is unlikely to be the result of static hybridization errors, since improperly assembled cages would be removed during the purification procedure. Rather, we suggest that random opening due to dynamic fluctuations of the structure even at $4{ }^{\circ} \mathrm{C}$ allowed entrance of small amounts of HRP giving rise to the low HRP activity level observed in sample 3.

We next investigated if a cage structure without hairpin-forming linkers in one corner could facilitate HRP uptake at $37^{\circ} \mathrm{C}$ via the apertures of the lattice. For this purpose we used the previously described Cage(7T) of which all corners are constituted by seven thymidine linkers, and which represent the largest of the already characterized cage structures. Hence, Cage(7T) is the member of the cage family without the hairpin-forming linkers that have the largest apertures in the lattice surrounding the central cavity. Cage(7T) was gel-purified and incubated with or without molar excess of HRP at temperatures ranging from 37 to $4{ }^{\circ} \mathrm{C}$ or at a constant temperature of $4{ }^{\circ} \mathrm{C}$ exactly as in the experiments performed with $\mathrm{Cage}_{\mathrm{hp}}(3 \mathrm{~T})$ described above. The result of measuring HRP activity using the spot test on cut-out gel pieces obtained in this experiment is shown in Figure $3 \mathrm{C}$ and demonstrates that HRP activity did not copurify with Cage(7T) under any of the investigated conditions (for quantification of the results, see Figure 3D). A similar result was observed when Cage(3T) (without the hairpin-forming extensions) was incubated with HRP under the described conditions (data not shown). This experiment excludes that the copurification of HRP with $\mathrm{Cage}_{\mathrm{hp}}$ (3T) was the result of unspecific interaction of HRP to the 


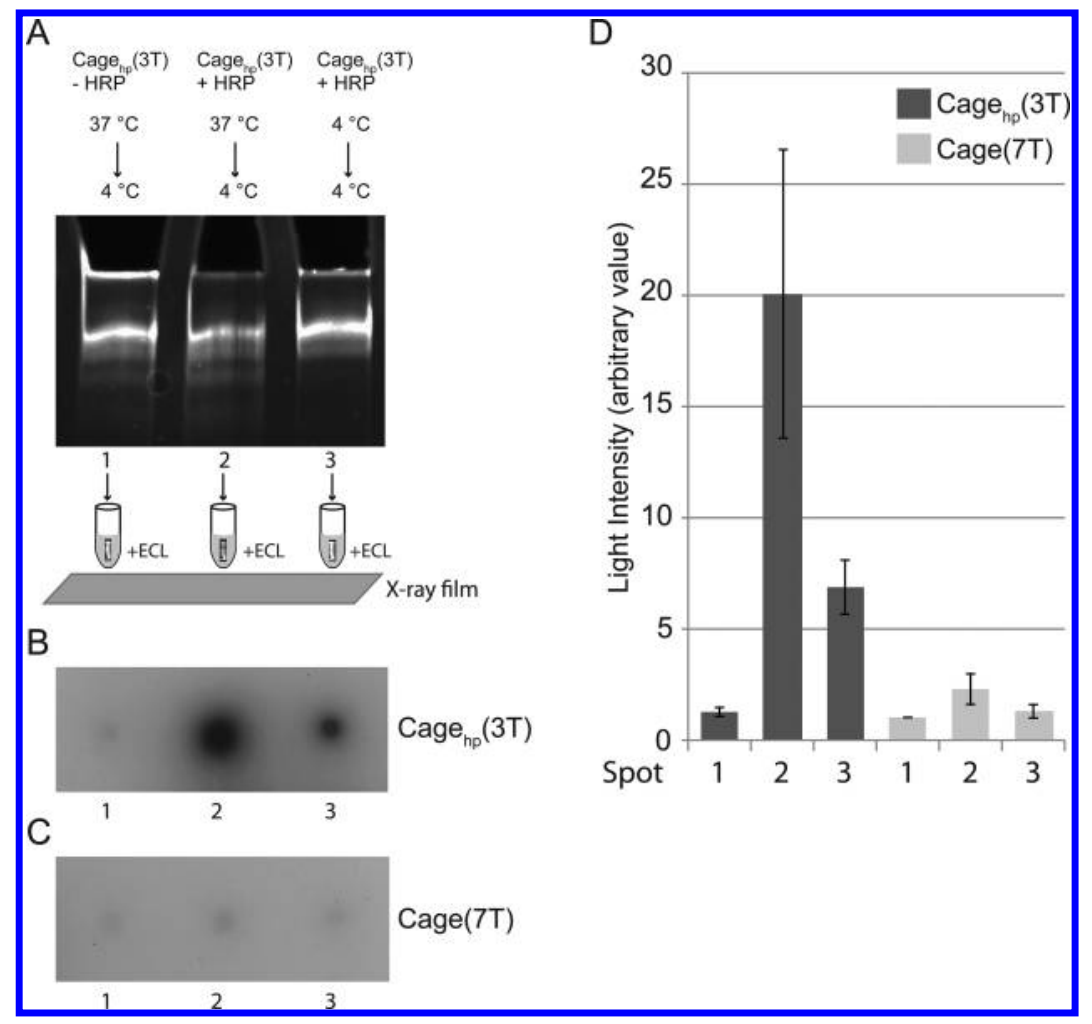

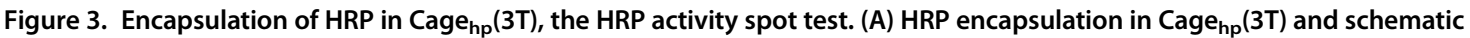
illustration of HRP activity spot test. Cage $\mathrm{hp}_{\mathrm{hp}}(3 \mathrm{~T})$ was incubated without (lane 1) or with (lane 2 and 3 ) HRP at either $37^{\circ} \mathrm{C}$ prior to slow cooling to $4{ }^{\circ} \mathrm{C}$ (lane 1 and 2) or at a constant temperature of $4{ }^{\circ} \mathrm{C}$ (lane 3) as indicated in the top panel. Subsequently the samples were subjected to native polyacrylamide gel-electrophoresis at $4{ }^{\circ} \mathrm{C}$, and the products were stained with $\mathrm{EtBr}$ (middle panel). The bands containing Cage $\mathrm{hp}_{\mathrm{h}}(3 \mathrm{~T})$ were cut out of the gel, washed, and mixed with the substrate (ECL) for HRP in $1.5 \mathrm{~mL}$ tubes placed on top of an X-ray film (lower panel). (B) Result of the HRP activity spot test. Spots $1-3$ show the results obtained when analyzing the Cage $\mathrm{hp}_{\mathrm{p}}(3 \mathrm{~T})$ bands cut out from lanes $1-3$ of the gel shown in (A). (C) Result of HRP activity spot test using Cage(7T) instead of Cage $\mathrm{hp}_{\mathrm{p}}(\mathrm{3T})$ in an experiment similar to the one schematically illustrated in (A). Spots $1-3$ same

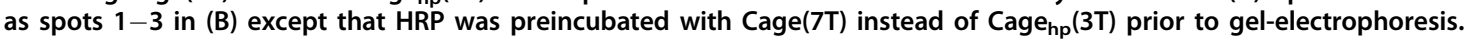
(D) Quantitative depiction of the results obtained by three individual experiments as the ones illustrated in (A-C). The spots were quantified using the Gel Analyzer Options and Wand tracing tool in ImageJ 1.46r. All spots were normalized to the background of the spot representing Cage(7T) without HRP giving that spot the value of 1 . Note that this method does not account for oversaturated spots.

outside of the cage structure and provides unambiguous evidence that the observed copurification was caused by encapsulation of HRP inside Cage $_{h p}(3 T)$.

Analysis of the Identity of the Encapsulated Enzyme Cargo by Mass Spectrometry. The presence of HRP in the Cage $_{h p^{-}}$ (3T) following incubation of the cage with molar excess of HRP at temperatures ranging from 37 to $4{ }^{\circ} \mathrm{C}$ and gel-purification as described was further investigated by MALDI-TOF mass spectrometry (MS) after trypsin digestion (see Supporting Information Figure S2). Two peptides corresponding to tryptic peptides from HRP (acc. no.: P59121) (Table 1) were observed in the digest of the DNA cage with HRP. The same peptides and an additional HRP peptide were observed in the control digest of HRP. Furthermore, eight peptides with identical masses not corresponding to tryptic HRP peptides were observed in the sample containing the cage encapsulated HRP and the control digest of HRP. This further supports the capture of proteins into the DNA cage, as the commercial HRP preparation utilized in the experiment was shown to contain proteins other than
TABLE 1. Identified HRP Peptides ${ }^{a}$

\begin{tabular}{lccl}
\multicolumn{1}{c}{ sample } & observed mass & theoretical mass & \multicolumn{1}{c}{ peptide } \\
\hline Cage-DNA & n.d. & & \\
Cage+HRP & 1073.61 & 1073.55 & ${ }^{85}$ TALERACPR $^{93}+1$ IAM \\
& 1079.50 & 1079.57 & ${ }^{76}$ GFNVIDRMK $^{84}$ \\
$250 \mathrm{ng} \mathrm{HRP}$ & 743.53 & 743.48 & ${ }^{32}$ IAASILR $^{38}$ \\
& 1073.60 & 1073.55 & ${ }^{85}$ TALERACPR $^{93}+1$ IAM \\
& 1079.57 & 1079.57 & ${ }^{76}$ GFNVIDRMK $^{84}$ \\
\hline
\end{tabular}

${ }^{a}$ The observed monoisotopic molecular masses were determined by MALDITOF-MS, and the theoretical tryptic masses are of HRP (acc. no.: P59121). IAM (iodoacetamide) denotes alkylation of cysteines in the identified peptide. n.d., no tryptic HRP peptides were detected.

HRP when subjected to gel-electrophoretic analysis (data not shown). In the MS spectrum of the gelpurified DNA cage incubated without HRP, only a few peaks with low intensity were observed, and none of these were present in the HRP control digest.

Estimation of the Encapsulation Efficiency. Attempts were made to estimate the encapsulation percentage, 


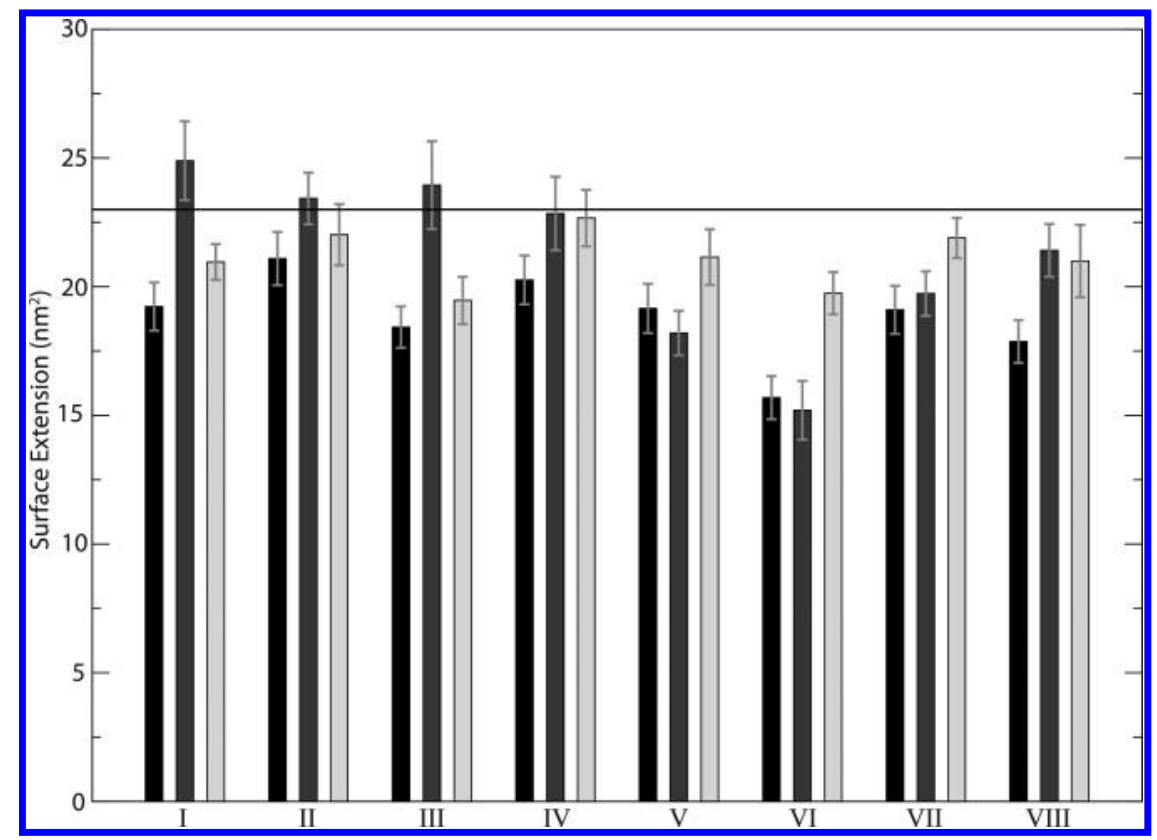

Figure 4. Average surfaces values of the eight hexagonal faces of the truncated octahedron calculated over the last $35 \mathrm{~ns}$ of the MD simulation for Cage hp (3T) at $277 \mathrm{~K} \mathrm{(black} \mathrm{bar)} \mathrm{and} \mathrm{at} 313 \mathrm{~K}$ (dark gray bar) and for Cage(7T) at $313 \mathrm{~K}$ (light gray bar) as control. The horizontal solid black line indicates the minimum surface required for HRP encapsulation.

i.e., the percentage of cages accommodating a HRP in their central cavity, by fluorescent labeling of the cage and the HRP entities. However, all attempts to encapsulate fluorescent-labeled HRP in $\mathrm{Cage}_{\mathrm{hp}}(3 \mathrm{~T})$ failed as measured by activity spot tests (see Figure $3 \mathrm{~A}$ and $\mathrm{B}$ ) as well as fluorescent visualization (data not shown). The reason for this is yet unknown but may reflect changes in the properties of HRP (charge or size) that renders its encapsulation impossible. Note, the failure to observe encapsulation of fluorescent-labeled HRP in activity spot assays was not caused by deactivation of HRP by the labeling process since the labeled HRP was fully active when compared to unlabeled HRP (data not shown). The encapsulation percentage was therefore estimated in terms of the HRP activity that copurified with a known amount of $\mathrm{Cage}_{\mathrm{hp}}(3 \mathrm{~T})$ in comparison to the HRP activity obtained by a titration of known concentrations of control HRP. The result of this estimation suggested that approximately $7 \%$ of the cages encapsulated a HRP enzyme after incubation with 25 times molar excess of HRP at $37{ }^{\circ} \mathrm{C}$ followed by slowly cooling to $4{ }^{\circ} \mathrm{C}$ (data not shown). As argued above, static hybridization errors in the

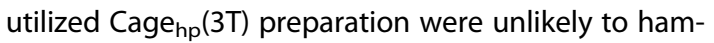
per encapsulation yield, since only correct assembled cages were selected by a thorough purification protocol. Rather, diffusion of HRP into the central cavity of the cage poses the most important limitation to encapsulation yield. Consistently, the encapsulation efficiency could be improved (3-4 fold) by mixing HRP and $\mathrm{Cage}_{\mathrm{hp}}(3 \mathrm{~T})$ in small (picoliter) incubators enabled by droplet microfluidics (Supporting Information Figure S3). The designed scheme of droplet-microfluidics was previously shown to generate a uniform and well-controlled microenvironment. Because of the short diffusion length and rapid mixing through the designed winding channel, ${ }^{45}$ a fully mixed state could be ensured, thereby promoting subsequent reactions. ${ }^{46}$

Molecular Mechanism of HRP Encapsulation in Cage $_{\mathbf{h p}}$ (3T). Simulation of $\operatorname{Cage}_{\mathrm{hp}}(3 \mathrm{~T})$ at two temperatures permits to propose the molecular mechanism behind the observed encapsulation of HRP when changing the temperature from 37 to $4{ }^{\circ} \mathrm{C}$. A plot of the root-meansquare fluctuations for each nucleotide indicates that such a value is larger for the simulation at high than at low temperature mainly at the level of the hairpin (Supporting Information Figure S4), but also for the double helices. This result suggests that $\mathrm{Cage}_{\mathrm{hp}}(3 \mathrm{~T})$ is characterized by a larger flexibility upon increasing the temperature, as confirmed by the analysis of the mean number of hydrogen bonds present during the simulation. The number of hydrogen bonds decreased for the simulation at $37^{\circ} \mathrm{C}$ not only at the level of the hairpins but also at the level of the double helices (Supporting Information Figure S5) indicating that at high temperature $\mathrm{Cage}_{\mathrm{hp}}(3 \mathrm{~T})$ is characterized by a relatively floppy structure. The decreased rigidity of the cage with increasing temperature had a direct influence on the average dimension of its hexagonal faces. These values are reported in Figure 4 for the simulation at $4{ }^{\circ} \mathrm{C}$ (black bars) and $37{ }^{\circ} \mathrm{C}$ (dark gray bars), respectively, together with an indication of the diameter of HRP. At $4{ }^{\circ} \mathrm{C}$ all the surfaces of the eight hexagonal faces of $\mathrm{Cage}_{\mathrm{hp}}(3 \mathrm{~T}) \mathrm{had}$ an average value that was below the diameter of HRP, while at $37^{\circ} \mathrm{C}$ the cage could undergo relatively large deformations that permitted the hexagonal faces to 
reach values larger than the HRP dimensions, providing an explanation for the entrance of the enzyme into the cage at high temperature. According to the simulation, the opening of $\mathrm{Cage}_{\mathrm{hp}}(\mathrm{3T})$ at high temperature may not necessarily be due to the unfolding of the hairpins toward single DNA strands but rather to a loosening of the structure. Hence, because of reduction of the average number of hydrogen bonds, the structure can undergo deformations that permit the widening of the hexagonal faces. The simulation did support that the increased cage flexibility at $37{ }^{\circ} \mathrm{C}$ is due to the presence of the hairpins since the original Cage(7T), simulated at $37{ }^{\circ} \mathrm{C}$, displays values of the hexagonal faces surfaces below the HRP average diameter (Figure 4, light gray bars).

The low level of HRP background activity observed for the $\mathrm{Cage}_{\mathrm{hp}}(3 \mathrm{~T})$ incubated with HRP at $4{ }^{\circ} \mathrm{C}$ (Figure $3 \mathrm{C}$ ) can possibly be explained by the occurrence of some fluctuations in the DNA at low temperature. This can be appreciated by looking at the value of a single surface averaged over each nanosecond of the simulation at both 4 and $37^{\circ} \mathrm{C}$ (Supporting Information Figure $\mathrm{S6}$ ). The figure shows that the surface reaches values larger than $\mathrm{HRP}$ in the simulation at $4{ }^{\circ} \mathrm{C}$ only on the first, eighth, and ninth nanosecond, while in the simulation at $37^{\circ} \mathrm{C}$ this occurs for a much larger time window.

Temperature-Controlled Release of HRP from Cage hp (3T). To investigate if the encapsulated HRP could be released from Cage $_{h p}(3 T)$ in a temperature-controlled manner, a sample with $\mathrm{Cage}_{\mathrm{hp}}(3 \mathrm{~T})$ encapsulated HRP was prepared and split in three before it was gel-purified as described in the Materials and Methods. One sample was used to confirm the presence of HRP activity in the sample and gave a result similar to the one obtained for sample 2 in Figure 3B (data not shown). The remaining two gel pieces containing the $\mathrm{Cage}_{\mathrm{hp}}{ }^{-}$ (3T) with HRP were incubated at either 4 or $37^{\circ} \mathrm{C}$ for $30 \mathrm{~min}$ before they were subjected to a second gelelectrophoretic run performed at 4 and $37{ }^{\circ} \mathrm{C}$, respectively. Potential HRP activity that copurified with the cage under these conditions was analyzed using the HRP activity spot test as described under Figure 3B. As evident from Figure $5 A$ and $B, C \operatorname{Cage}_{h p}(3 T)$ retained HRP activity after incubation and a second gelelectrophoretic run at $4{ }^{\circ} \mathrm{C}$, while HRP activity was lost after incubation and a second gel-electrophoresis at $37{ }^{\circ} \mathrm{C}$. These results are consistent with temperaturecontrolled release of HRP from the $\operatorname{Cage}_{\mathrm{hp}}(3 \mathrm{~T})$ at $37^{\circ} \mathrm{C}$, and the presented results demonstrated a strong proof of concept of the principle for easy controllable and reversible encapsulation of a protein entity in a DNA nanocage.

One of the suggested potential applications for $3 \mathrm{D}$ cage or box-shaped DNA structures is for the controlled delivery for biomolecules to cells. Although the temperature-controlled encapsulation-release

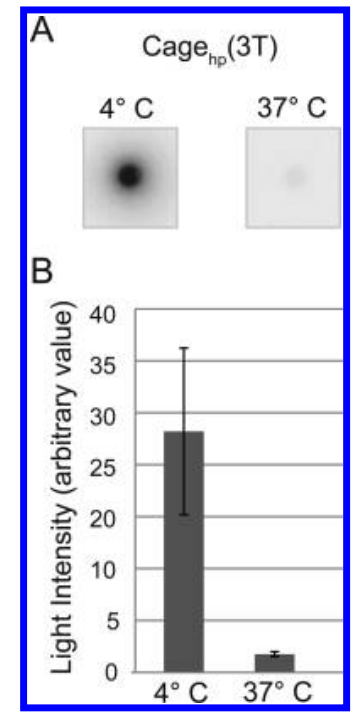

Figure 5. Release of HRP from Cage $\mathrm{hp}_{\mathrm{h}}(3 \mathrm{~T})$. (A) HRP was encapsulated in Cage $_{\mathrm{hp}}(\mathrm{3T})$ and the cage with HRP gel-purified as shown in Figure 3. Subsequently, the samples were preincubated and separated by gel-electrophoresis at 4 or $37^{\circ} \mathrm{C}$ as indicated. Bands containing Cage $\mathrm{hp}_{\mathrm{hp}}$ (3T) were cut out of the gel and analyzed for HRP activity using the spot test schematically illustrated in Figure 3A. The resulting X-ray images are shown. (B) Quantitative depiction of the results obtained by three individual experiments as the one described in (A).

mechanism utilized in the current study is not feasible for controlled drug release in living organisms, we used the current design as a simple model to investigate if the cage structure can act as a carrier to promote cellular uptake of HRP. For this purpose we used Sf9 insect cells, which can be cultivated and maintained at $15{ }^{\circ} \mathrm{C}$ and, hence, kept cold enough to allow uptake of the $\mathrm{Cage}_{\mathrm{hp}}{ }^{-}$ (3T) containing HRP without risking cargo release. Cellular uptake of HRP was facilitated by encapsulation in the cage structure when combined with lipofectamine (Supporting Information Figure S7) but not in the absence of a tranfection agent (data not shown). This is in contrast with the previously reported cellular uptake of a tetrahedron by HEK293 cells in the absence of any transfection reagent. ${ }^{36}$ HEK293 cells belong to a group of relatively easily transfectable cells. ${ }^{47}$ Hence, the difference in cellular uptake may be caused by the different cell types utilized. Alternatively, the different properties of the tetrahedra used in the previous studies and the cargo containing octahedron cage structure utilized here may pose different challenges to cellular uptake. Attempts to direct and facilitate the cage uptake to specific cell types and in the absence of transfection agents is out of the scope of the present study but may be achievable by the coupling of cell-penetrating peptides, ${ }^{48}$ DNA aptamers, ${ }^{49}$ or folate as previously demonstrated. ${ }^{37}$ For controlled release of cargo in response to specific biological environments, it will be necessary to replace the hairpin-forming linkers used in the current study with for instance G-quadruplexforming sequences, aptamers or other specific sequences of which the conformation can be changed in response 
to the ionic composition or biomolecules in the surroundings. $^{50-52}$ This is again beyond the scope of the current study, which is to demonstrate efficient and reversible encapsulation-release of an enzyme cargo in a preassembled DNA cage facilitated purely by diffusion. An important take-home message from the current study, which demonstrates the ability of HRP to convert substrates, even when encapsulated in the cage, is that cargo release may not always be necessary for biomedical purposes. Hence, conversion of small prodrugs to the active metabolite catalyzed by enzymes encapsulated in suitable DNA containers directed to specific cells or compartments of the body can be envisioned.

Given that the spatial constraint of the cavity of $\mathrm{Cage}_{\mathrm{hp}}(3 \mathrm{~T})$ allows encapsulation of one and only one enzyme cargo per cage with a relatively high yield (up to $20-30 \%$, using droplet microfluidics to promote efficient mixing) of enzyme containing DNA cages, the presented design may serve as a building block for higher order structures composed of specific bioreactor entities (Cage $_{\mathrm{hp}}(\mathrm{3T})$ with its cargo). In such structures the enzyme containing cage modules may be connected in a precisely programmable manner by branched molecules as for instance the three-way oligonucleotides presented by Lundberg et al. to allow the construction of fairly complex networks with a decent yield. ${ }^{44}$

\section{CONCLUSION}

In the present study we demonstrated temperaturecontrolled encapsulation and release of the enzyme HRP using a preassembled and covalently closed DNA cage structure as a carrier. This is to our knowledge the first example of a fully preassembled DNA cage facilitating reversible and controlled encapsulation and release of an enzyme cargo without any form of covalent or noncovalent attachment of the cargo.

The utilized DNA cage $\left(\right.$ Cage $\left._{h p}\right)$ was based on the basic structure of the cage family previously published from our group, all having an overall structure of a truncated octahedron. ${ }^{20,21}$ As in the previously published structures, the edges of Cage $\mathrm{h}_{\mathrm{hp}}$ were composed of 12 double-stranded B-DNA helices interrupted by truncated corners composed of short single-stranded thymidine linkers except in one corner where the thymidine linkers were replaced by 32 nt stretches of DNA with the capability to fold into hairpin structures. The introduction of such hairpin-forming strands into the basic cage structure imposed sufficient flexibility for it to attain a temperaturedependent conformational transition large enough to facilitate entrance of HRP into its central cavity at $37^{\circ} \mathrm{C}$, retain it there at $4{ }^{\circ} \mathrm{C}$ and facilitate its release at $37{ }^{\circ} \mathrm{C}$ as demonstrated by gel-electrophoretic analyses. Encapsulation and release of HRP was strictly dependent on the hairpin-forming strands in one corner of the cage structure, and the Cage(7T) lacking the hairpins were unable to encapsulate HRP. These observations were in agreement with the MD simulations at $37^{\circ} \mathrm{C}$.

Though beyond the scope of this manuscript, several potential applications, within the fields of drug delivery and single molecule detection, are anticipated with the presented DNA nanocage. The encapsulation of HRP inside the DNA cage allowed its transfection into insect cells, which was not achievable using naked enzyme. This suggests the potential future use of DNA carriers to facilitate cellular uptake of enzyme drugs, although the temperature-controlled cargo release presented in the current study is not suitable for in vivo applications. Rather, the current nanocage may serve as a unique and facile biomanipulator to confine and arrange a controlled number of biomolecules in an orderly manner. Such applications would facilitate single molecule research by reducing the extensive labor requirements impeding some of the well-known technologies for precise physical manipulation of single molecule structures such as atomic force microscope (AFM), optical and magnetic tweezers. ${ }^{53}$

\section{MATERIALS AND METHODS}

Enzymes and Reagents. T4 polynucleotide kinase, T4 DNA Ligase, and BSA (New England Biolabs). ATP, ECL Plus Western blot detection system, High Performance Chemiluminescence film (Amersham Biopharma). Synthetic DNA substrates were purchased from GeneLink and DNA Technology. Horseradish Peroxidase (Sigma Aldrich). Typhoon TRIO scanner, Variable Mode Imager (Amersham Bioscience).

Design of Oligonucleotides for All DNA Cages. The sequences of the oligonucleotides were chosen using a computer program that minimized unwanted base pairing of the following three types: (i) annealing between different oligonucleotides, (ii) annealing between two identical oligonucleotides, and (iii) annealing within a single oligonucleotide. This was done under the constraints defined by the desired structure and the different desired melting temperatures for the interactions (Table 2).
TABLE 2. Oligonucleotides for DNA Cages

DNA oligonucleotides for Cage(nT), $n=3,7$

0L1 $1_{\text {nT }}$ GCCACCAGG(T) $)_{n}$ GATGTCTAAGCTGACCG(T) $)_{n}$ GGACCGTGATTCCATGAC(T) ${ }_{n}$ (TTAGAGTT

$0 \mathrm{~L} 2_{n T}$ TGGCTACAG(T) $)_{n}$ GGTCAGCTAGACATCG(T) $)_{n}$ GAATCCTATGCTCGGACG(T) ${ }_{n}$ GGCTCACAT

$03_{n}$ TCACGGTCC(T) ${ }_{n}$ (TATCCGATCGAGGCATG(T) ${ }_{n}$ CATACTGAGAGCGTTCCG(T) $n$ GTCATGGAA

$0\left\llcorner 4_{n T} \text { CAGATACGC(T) }\right)_{n}$ (ATGCCTCGATCGGATAG(T) $)_{n}$ (TGTAGCCAATGTGAGCC(T) $)_{n}$ GTGGCAGTT

$05_{n T}$ CTCAGTATG(T) $)_{n}$ CGGTTACGGTACAATGCC(T) ${ }_{n}$ (GCAAGACGTTAGTGTCC(T) ${ }_{n}$ CGGAACGCT

$0 \mathrm{~L} 6_{n T}$ GGTGTATCG(T) $)_{n}$ GGCATTGTACCGTAACCG(T) ${ }_{n}$ GCGTATCTGAACTGCGAC(T) ${ }_{n}$ CCACCGAAT

$0 \mathrm{~L} 7_{\mathrm{nT}} \quad$ CGTCTTGCG(T) $)_{n}$ GTATGACGCAGCACTTGC(T) ${ }_{n} \mathrm{CCTGGTGGCAACTCTAAG(T)_{n } G G -}$ ACACTAA

$0 \mathrm{~L} 8_{n T}$ ATAGGATTC(T) $)_{n}$ GCAAGTGCTGCGTCATAC(T) $)_{n}$ CGATACACCATTCGGTGG(T) ${ }_{n} \mathrm{CG}-$ TCCGAGC 
DNA oligonucleotides for Cage $_{h p}(n T), n=3$ (and $015_{n T}-0 \mathrm{~L} 8_{n T}, n=3$ )

$01 \mathrm{hp}_{\mathrm{nT}} \quad$ GCCACCAGG(T) ${ }_{n}$ GATGTCTAAGCTGACCGTCGAATATTTATCCCCCCCCATAAATATTCCTGGACCGTGATTCCATGAC(T) $)_{n}$ TTAGAGTT

02hp $\mathrm{p}_{\mathrm{nT}}$ TGGCTACAGTGGAATATTTATCCCCCCCCATAAATATTCCTCGGTCAGCTTAGACATGG(T) $)_{n}$ GATCCTATGCTGGACG(T) $)_{n}$ GGCTCACAT

03hp $\mathrm{p}_{\mathrm{nT}}$ TCACGGTCCTCGAATATTTATCCCCCCCCATAAATATTCCTCTATCCGATCGAGGCATG(T) ${ }_{n}$ (ATACTGAGAGCGTTCCG(T) $)_{n}$ GTCATGGAA

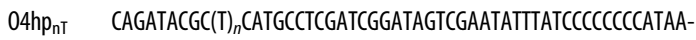
ATATTCCTCTGTAGCCAATGTGAGCC(T) $)_{n}$ GTGCAGTT

Assembly of DNA Cages. DNA Cage $\mathrm{hp}_{\mathrm{h}}(3 \mathrm{~T})$ and Cage(7T) were assembled by mixing the eight appropriate oligonucleotides (purchased gel-purified from GeneLink) in equimolar amounts in an assembly buffer containing $50 \mathrm{mM}$ Tris- $\mathrm{HCl}(\mathrm{pH} 7.5)$, $10 \mathrm{mM} \mathrm{MgCl}$, $10 \mathrm{mM}$ dithiothreitol, $1 \mathrm{mM} \mathrm{ATP}$, and $25 \mathrm{mg} /$ $\mathrm{mL}$ of bovine serum albumin. Phosphates were added to the $5^{\prime}$-ends by incubation with T4 polynucleotide kinase for $30 \mathrm{~min}$ at $37^{\circ} \mathrm{C}$. Subsequently, the samples were heated to $65^{\circ} \mathrm{C}$ for $10 \mathrm{~min}$ and cooled by $0.25^{\circ} \mathrm{C} / \mathrm{min}$ until the sample reached a temperature of $30^{\circ} \mathrm{C}$, where T4 DNA ligase was added. Cooling was continued by $0.25^{\circ} \mathrm{C} / \mathrm{min}$ until $16^{\circ} \mathrm{C}$. Subsequently the samples were incubated for $16 \mathrm{~h}$ at $16^{\circ} \mathrm{C}$ to ensure efficient ligation.

Gel-Electrophoresis and Purification of the DNA Cages. The partly or fully assembled $\mathrm{Cage}_{\mathrm{hp}}(3 \mathrm{~T})$ and Cage(7T) were analyzed on native gels following standard procedures. ${ }^{20}$ All products were visualized by staining the gels with ethidium bromide $(\mathrm{EtBr})$. Note that for the gel-electrophoresis stated in the text to be performed at either 4 or $37^{\circ} \mathrm{C}$, all buffers and gel equipment were cooled or heated to the appropriate temperature before loading of the gels. Furthermore the gels were run in a room with the appropriate temperature. If no specific temperature is indicated, gel-electrophoresis was performed at room temperature. The fully assembled cages were purified from a native gel by excision of the band representing the product, followed by soaking the gel-slice in elution buffer $\left(500 \mathrm{mM} \mathrm{NH}_{4} \mathrm{Ac}, 10 \mathrm{mM}\right.$ $\mathrm{MgAc}_{2}, 0.1 \mathrm{mM}$ EDTA (pH 8.0), $0.1 \% \mathrm{SDS}$ ) for $48 \mathrm{~h}$ at $30^{\circ} \mathrm{C}$ and $\mathrm{EtOH}$ precipitated. The eluted DNA cages were purified on a QIAGEN-tip 500 column (from QIAGEN Plasmid Maxi kit), following the standard procedure from the kit. The cages were eluted from the column in $300 \mathrm{~mL}$ fractions, and $\mathrm{EtOH}$ precipitated.

HRP Enzyme Encapsulation in Cage $(3 T)$ and HRP Activity Spot Test. $0.2 \mu \mathrm{g}$ of $\mathrm{Cage}_{\mathrm{hp}}(3 \mathrm{~T})$ or Cage(7T) was incubated with $1 \mu \mathrm{g}$ of HRP in $10 \mathrm{mM}$ Tris- $\mathrm{HCl} \mathrm{pH} 7.5$ for $15 \mathrm{~min}$ at $37^{\circ} \mathrm{C}$. $1 \mathrm{mM}$ spermidine and $2 \mathrm{mM} \mathrm{MgCl}$, were added before carefully mixing the samples and cooling to $4{ }^{\circ} \mathrm{C}$ over a time interval of $15 \mathrm{~min}$. Samples were subjected to $5 \%$ native $1 \times$ TBE gelelectrophoresis at the temperatures stated in the text and stained in $\mathrm{EtBr}$ before the bands of interest were cut from the gel and placed in individual Eppendorf tubes. Each cut out band was washed in $1 \mathrm{~mL}$ of $4{ }^{\circ} \mathrm{C} 1 \times$ TBE buffer twice. $100 \mathrm{~mL} 1 \times$ TBE with $10 \times$ diluted HRP substrate (ECL Plus Western blot detection system) was added to each tube in a dark room. The Eppendorf tubes were placed on top of an X-ray film for 5, 10, $30,60,120 \mathrm{~s}$, respectively, before the films were developed. Quantification of the spots on the films was performed using ImageJ64 1.46r.

Cage $_{h p}(3 \mathrm{~T})$ Modeling. The hairpin-loop model was realized using SYBYL 6.0 (TRIPOS, http://www.tripos.com) and PyMOL (The PyMOL Molecular Graphics System, Version 1.4, Schrödinger, LLC). As a first step, a 10 base-pair B-DNA helix was generated using the SYBYL Biopolymer module, then two nucleotides were added to the $5^{\prime}$ end of a strand and to the $3^{\prime}$ end of the complementary strand, in order to model the extremities required to connect the hairpin-loop to the Cage(3T) double helices. At the opposite end of the two strands four cytosines were added to each strand in order to build a loop, modeled using the PyMOL Sculpting module (that works like a real-time energy minimizer), imposing the eight cytosines to reach a closed circular conformation. The final model was imported in SYBYL for an energy minimization through the ANNEAL module, to remove any unfavorable interaction.
The Cage $_{h p}(3 T)$ model was realized starting from a coarse grain model of Cage(3T), previously generated to realize Cage(3T), Cage(5T), and Cage(7T)) atomistic models, ${ }^{54,55}$ in which every sphere matches a phosphate atom of a nucleotide. A Ruby script was realized, which according to the base numbering in the coarse grain template, generates a second script including the spatial definition of the atoms recognized by the SYBYL software, which generates a first atomistic model of the double helices and thymidine linkers, fitting the nucleotides on the coarse grain template's spheres. Four copies of the hairpin-loop were manually added to the structure. Unfavorable interactions between the double helices, the linkers and the hairpinsloop were removed by local minimization through the SYBYL ANNEAL module. A second global minimization was carried out through the SYBYL MAXIMIN module. Finally the model was saved and exported in the PDB file format. ${ }^{56}$ The size of HRP was evaluated from the PDB file number $1 \mathrm{HCH}$ using the VMD program. $^{57}$

MD Simulations of Cage $_{h p}(3 T)$. The topology of $\mathrm{Cage}_{\mathrm{hp}}(3 \mathrm{~T})$ was obtained through the tLeap AMBER 10 suite program module. ${ }^{58}$ The structure was parametrized using the AMBERO3 forcefield. ${ }^{59}$ The MD simulated structures were immersed in a truncated octahedral water box, using TIP $3 \mathrm{P}^{60}$ water molecules and neutralizing the charges with $620 \mathrm{Na}+$ counterions, placed in electrostatically preferred positions, imposing a minimal distance between the solute and the box walls of $14 \AA$. The final system consists of 484986 atoms. Three minimizations were carried out before running the simulations: the first, in which restraints of $500 \mathrm{kcal} / \mathrm{mol}$ have been imposed on all of the DNA cage atoms to minimize the water and the ions; the second, in which restraints of $500 \mathrm{kcal} / \mathrm{mol}$ have been imposed on the double helices only, to minimize the thymidine linkers and the hairpins-loop; and the third, executed without imposing restraints, to minimize the entire system. After this, a thermalization procedure was carried out, in order to gradually increase system temperature from 0 to $277 \mathrm{~K}$ for the first simulation and from 0 to $313 \mathrm{~K}$ for the second. The simulations were carried out through the NAMD $2.8 \mathrm{~b} 3^{61}$ program. The system was simulated for $50 \mathrm{~ns}$ in periodic boundary conditions, using a cutoff of $10 \AA$ for the evaluation of short-range nonbonded interactions and the $\mathrm{PME}^{62}$ method for the long-range electrostatic interactions. The temperature was fixed at 277 or $313 \mathrm{~K}$, for the low and high temperature simulations, respectively, using Langevin dynamics, 63 whereas pressure was held constant at 1 ATM through the Langevin piston method. ${ }^{64}$ The SHAKE ${ }^{65}$ and SETTLE ${ }^{66}$ algorithms were used to restrain bond lengths, for nucleic acid and water molecules, respectively. The atomic positions were saved every 250 steps (i.e., 0.5 ps) for the analyses.

The same procedure was used to obtain the Cage(7T) system topology and the MD simulations were carried out using the same parameters. The systems were simulated using $16 \mathrm{FN}$ nodes, for a total of 2048 cores, on the Curie Cluster at the TGCC at Centre CEA-DAM lle de France in France.

Standard Analysis. Root-mean-square fluctuations (RMSF) were calculated by using the GROMACS $4^{67,68}$ g_rmsf module, which is an analysis tool able to evaluate the amplitude of fluctuations with respect to the time averaged atoms positions. Hydrogen Bond analysis was performed through the $\mathrm{VMD}^{57}$ plugin $\mathrm{H}$-Bonds, to obtain the $\mathrm{H}$-Bonds average values over the trajectory considering, time by time, the entire $\mathrm{Cage}_{\mathrm{hp}}(3 \mathrm{~T})$, the double helices only and the hairpins-loop only. Surfaces analyses were carried out through an in house built program over the last $35 \mathrm{~ns}$ (the fully thermalized part) of the trajectories. All the images were obtained through the CHIMERA ${ }^{69}$ program. Plots were obtained through the plotting program GRACE (http://plasmagate.weizmann.ac.il/Grace/).

Analysis of Tryptic Peptides. Excised gel pieces corresponding to DNA Cage hp $_{\mathrm{h}}(3 \mathrm{~T})$ with or without encapsulated HRP were incubated in $20 \mathrm{mM}$ Tris- $\mathrm{HCl}, 100 \mathrm{mM} \mathrm{NaCl}, \mathrm{pH} 7.5$ at $37{ }^{\circ} \mathrm{C}$ overnight. As a control, $250 \mathrm{ng}$ of the HRP preparation were incubated under the same conditions. The gel pieces were removed, and all samples were added 1,4-dithioerythritol (to $10 \mathrm{mM}$ ) and incubated at $56^{\circ} \mathrm{C}$ for $45 \mathrm{~min}$. Free cysteines were alkylated by addition of iodoacetamide (IAM, to $50 \mathrm{mM}$ ) and incubation for $30 \mathrm{~min}$ in the dark at room temperature. 
Sequencing grade modified trypsin (Promega) was added, followed by incubation at $37^{\circ} \mathrm{C}$ overnight. The samples were analyzed by matrix-assisted laser desorption ionization timeof-flight mass spectrometry (MALDI-TOF-MS) using a Voyager DE-PRO mass spectrometer (Applied Biosystems). The theoretical peptide masses of HRP were calculated using the GPMAW program (Lighthouse Data).

Conflict of Interest: The authors declare no competing financial interest.

Acknowledgment. We thank associate professor Pia Møller Martensen and technician Astrid van der Aa Kühle for assistance with the Sfg cells. This work was supported by grants from the Aase og Ejnar Danielsens Foundation, the Fabrikant Einar Willumsens Mindelegat, the Friedrich Wilhelm Frank \& Hustru Angelina Franks Mindelegat, the Arvid Nilssons Foundation, the Minister Erna Hamiltons Legat for Videnskab og Kunst, the Familien Erichsens Mindefond, the Lundbeck Foundation (R95-A10275 to Y.P.H.), and the Danish Council for Independent Research's research carrier program Sapere Aude (S.L.K. and V.B.). S.J. was supported by the Danish Research Council (11-105736/FSS). The MD calculations have been carried out under the PRACE Project No. 2012071230.

Supporting Information Available: Fluorescence quenching experiments, MALDI-TOF-MS of tryptic peptides, HRP encapsulation in $\operatorname{Cage}_{\mathrm{hp}}(3 \mathrm{~T})$ using microfluidics, molecular dynamic simulations, and cotransfection of HRP with Cage $\mathrm{hp}_{\mathrm{hp}}(\mathrm{BT})$ in insect cells. This material is available free of charge via the Internet at http://pubs.acs.org.

\section{REFERENCES AND NOTES}

1. Lo, P. K.; Metera, K. L.; Sleiman, H. F. Self-Assembly of ThreeDimensional DNA Nanostructures and Potential Biological Applications. Curr. Opin. Chem. Biol. 2010, 14, 597-607.

2. Li, H.; Labean, T. H.; Leong, K. W. Nucleic Acid-Based Nanoengineering: Novel Structures for Biomedical Applications. Interface Focus 2011, 1, 702-724.

3. Seeman, N. C. Nucleic Acid Junctions and Lattices. J. Theor. Biol. 1982, 99, 237-427.

4. Malo, J.; Mitchell, J. C.; Venien-Bryan, C.; Harris, J. R.; Wille, H.; Sherratt, D. J.; Turberfield, A. J. Engineering a 2D Protein-DNA Crystal. Angew. Chem., Int. Ed. Engl. 2005, 44, 3057-3061.

5. Selmi, D. N.; Adamson, R. J.; Attrill, H.; Goddard, A.; Gilbert, R. J. C.; Watts, A.; Turberfield, A. J. DNA-Templated Protein Arrays for Single-Molecule Imaging. Nano Lett. 2011, 11, 657-660.

6. Winfree, E.; Liu, F.; Wenzler, L. A.; Seeman, N. C. Design and Self-Assembly of Two-Dimensional DNA Crystals. Nature 1998, 394, 539-544.

7. Zheng, J.; Birktoft, J. J.; Chen, Y.; Wang, T.; Sha, R.; Constantinou, P. E.; Ginell, S. L.; Mao, C.; Seeman, N. C. From Molecular to Macroscopic via the Rational Design of a SelfAssembled 3D DNA Crystal. Nature 2009, 461, 74-77.

8. Rendek, K. N.; Fromme, R.; Grotjohann, I.; Fromme, P. Crystallization of a Self-Assembled Three-Dimensional DNA Nanostructure. Acta Crystallogr., Sect. F: Struct. Biol. Cryst. Commun. 2013, 69, 141-146.

9. Subramani, R.; Juul, S.; Rotaru, A.; Andersen, F. F.; Gothelf, K. V.; Mamdouh, W.; Besenbacher, F.; Dong, M.; Knudsen, B. R. A Novel Secondary DNA Binding Site in Human Topoisomerase I Unravelled by Using a 2D DNA Origami Platform. ACS Nano 2010, 4, 5969-5977.

10. Zhang, C.; Su, M.; He, Y.; Zhao, X.; Fang, P. A.; Ribbe, A. E.; Jiang, W.; Mao, C. Conformational Flexibility Facilitates Self-Assembly of Complex DNA Nanostructures. Proc. Natl. Acad. Sci. U. S. A. 2008, 105, 10665-10669.

11. Aldaye, F. A.; Sleiman, H. F. Modular Access to Structurally Switchable 3D Discrete DNA Assemblies. J. Am. Chem. Soc. 2007, 129, 13376-13377.

12. Yang, H.; McLaughlin, C. K.; Aldaye, F. A.; Hamblin, G. D.; Rys, A. Z.; Rouiller, I.; Sleiman, H. F. Metal-Nucleic Acid Cages. Nat. Chem. 2009, 1, 390-396.
13. Zimmermann, J.; Cebulla, M. P.; Monninghoff, S.; von Kiedrowski, G. Self-Assembly of a DNA Dodecahedron from 20 Trisoligonucleotides with $\mathrm{C}(3 \mathrm{~h})$ Linkers. Angew. Chem., Int. Ed. Enal. 2008, 47, 3626-3630.

14. Goodman, R. P.; Schaap, I. A.; Tardin, C. F.; Erben, C. M.; Berry, R. M.; Schmidt, C. F.; Turberfield, A. J. Rapid Chiral Assembly of Rigid DNA Building Blocks for Molecular Nanofabrication. Science 2005, 310, 1661-1665.

15. Li, Z.; Wei, B.; Nangreave, J.; Lin, C.; Liu, Y.; Mi, Y.; Yan, H. A Replicable Tetrahedral Nanostructure Self-Assembled from a Single DNA Strand. J. Am. Chem. Soc. 2009, 131, 13093-13098.

16. Kato, T.; Goodman, R. P.; Erben, C. M.; Turberfield, A. J.; Namba, K. High-Resolution Structural Analysis of a DNA Nanostructure by CryoEM. Nano Lett. 2009, 9, 2747-2750.

17. He, Y.; Ye, T.; Su, M.; Zhang, C.; Ribbe, A. E.; Jiang, W.; Mao, C. Hierarchical Self-Assembly of DNA into Symmetric Supramolecular Polyhedra. Nature 2008, 452, 198-201.

18. Chen, J. H.; Seeman, N. C. Synthesis from DNA of a Molecule with the Connectivity of a Cube. Nature 1991, $350,631-633$.

19. Zhang, C.; Ko, S. H.; Su, M.; Leng, Y.; Ribbe, A. E.; Jiang, W.; Mao, C. Symmetry Controls the Face Geometry of DNA Polyhedra. J. Am. Chem. Soc. 2009, 131, 1413-1415.

20. Andersen, F. F.; Knudsen, B.; Oliveira, C. L.; Frohlich, R. F.; Kruger, D.; Bungert, J.; Agbandje-McKenna, M.; McKenna, R.; Juul, S.; Veigaard, C.; et al. Assembly and Structural Analysis of a Covalently Closed Nano-Scale DNA Cage. Nucleic Acids Res. 2008, 36, 1113-1119.

21. Oliveira, C. L.; Juul, S.; Jorgensen, H. L.; Knudsen, B.; Tordrup, D.; Oteri, F.; Falconi, M.; Koch, J.; Desideri, A.; Pedersen, J. S.; et al. Structure of Nanoscale Truncated Octahedral DNA Cages: Variation of Single-Stranded Linker Regions and Influence on Assembly Yields. ACS Nano 2010, 4, 1367-1376.

22. Zhang, Y.; Seeman, N. C. Construction of a DNA-Truncated Octahedron. J. Am. Chem. Soc. 1994, 116, 1661-1669.

23. Shih, W. M.; Quispe, J. D.; Joyce, G. F. A 1.7-Kilobase SingleStranded DNA that Folds into a Nanoscale Octahedron. Nature 2004, 427, 618-621.

24. He, Y.; Su, M.; Fang, P. A.; Zhang, C.; Ribbe, A. E.; Jiang, W.; Mao, C. On the Chirality of Self-Assembled DNA Octahedra. Angew. Chem., Int. Ed. Enql. 2010, 49, 748-51.

25. Erben, C. M.; Goodman, R. P.; Turberfield, A. J. A SelfAssembled DNA Bipyramid. J. Am. Chem. Soc. 2007, 129, 6992-6993.

26. Bhatia, D.; Mehtab, S.; Krishnan, R.; Indi, S. S.; Basu, A.; Krishnan, Y. Icosahedral DNA Nanocapsules by Modular Assembly. Angew. Chem., Int. Ed. Engl. 2009, 48, 41344137.

27. Andersen, E. S.; Dong, M.; Nielsen, M. M.; Jahn, K.; Subramani, R.; Mamdouh, W.; Golas, M. M.; Sander, B.; Stark, H.; Oliveira, C. L.; et al. Self-Assembly of a Nanoscale DNA Box with a Controllable lid. Nature 2009, 459, 73-76.

28. Dietz, H.; Douglas, S. M.; Shih, W. M. Folding DNA into Twisted and Curved Nanoscale Shapes. Science 2009, 325, 725-730.

29. Douglas, S. M.; Dietz, H.; Liedl, T.; Hogberg, B.; Graf, F.; Shih, W. M. Self-Assembly of DNA into Nanoscale ThreeDimensional Shapes. Nature 2009, 459, 414-418.

30. Endo, M.; Hidaka, K.; Kato, T.; Namba, K.; Sugiyama, H. DNA Prism Structures Constructed by Folding of Multiple Rectangular Arms. J. Am. Chem. Soc. 2009, 131, 1557015571.

31. Douglas, S. M.; Bachelet, I.; Church, G. M. A Logic-Gated Nanorobot for Targeted Transport of Molecular Payloads. Science 2012, 335, 831-834.

32. Goodman, R. P.; Heilemann, M.; Doose, S.; Erben, C. M.; Kapanidis, A. N.; Turberfield, A. J. Reconfigurable, Braced, Three-Dimensional DNA Nanostructures. Nat. Nanotechnol. 2008, 3, 93-96.

33. Banerjee, A.; Bhatia, D.; Saminathan, A.; Chakraborty, S.; Kar, S.; Krishnan, Y. Controlled Release of Encapsulated Cargo from a DNA Icosahedron using a Chemical Trigger. Angew. Chem., Int. Ed. Engl. 2013, 52, 6854-6857. 
34. Keum, J. W.; Bermudez, H. Enhanced Resistance of DNA Nanostructures to Enzymatic Digestion. Chem. Commun. (Cambridge, U. K.) 2009, 7036-7038.

35. Mei, Q.; Wei, X.; Su, F.; Liu, Y.; Youngbull, C.; Johnson, R.; Lindsay, S.; Yan, H.; Meldrum, D. Stability of DNA Origami Nanoarrays in Cell Lysate. Nano Lett. 2011, 11, 1477-1482.

36. Walsh, A. S.; Yin, H.; Erben, C. M.; Wood, M. J.; Turberfield, A. J. DNA Cage Delivery to Mammalian Cells. ACS Nano 2011, 5, 5427-5432.

37. Ko, S.; Liu, H.; Chen, Y.; Mao, C. DNA Nanotubes as Combinatorial Vehicles for Cellular Delivery. Biomacromolecules 2008, 9, 3039-3043.

38. Erben, C. M.; Goodman, R. P.; Turberfield, A. J. SingleMolecule Protein Encapsulation in a Rigid DNA Cage. Angew. Chem. Int. Ed. Engl. 2006, 45, 7414-7417.

39. Zhao, Z.; Jacovetty, E. L.; Liu, Y.; Yan, H. Encapsulation of Gold Nanoparticles in a DNA Origami Cage. Angew. Chem. Int. Ed. Engl. 2011, 50, 2041-2044.

40. Flory, J. D.; Shinde, S.; Lin, S.; Liu, Y.; Yan, H.; Ghirlanda, G.; Fromme, P. PNA-Peptide Assembly in a 3D DNA Nanocage at Room Temperature. J. Am. Chem. Soc. 2013, 135, 69856993.

41. Crawford, R.; Erben, C. M.; Periz, J.; Hall, L. M.; Brown, T.; Turberfield, A. J.; Kapanidis, A. N. Non-Covalent Single Transcription Factor Encapsulation Inside a DNA Cage. Angew. Chem., Int. Ed. Engl. 2013, 52, 2284-2288.

42. Lin, C.; Liu, Y.; Yan, H. Designer DNA Nanoarchitectures. Biochemistry 2009, 48, 1663-1674.

43. Berglund, G. I.; Carlsson, G. H. Smith, A. T; Szoke, H.; Henriksen, A.; Hajdu, J. The Catalytic Pathway of Horseradish Peroxidase at High Resolution. Nature 2002, 417, 463-468.

44. Lundberg, E. P.; Plesa, C.; Wilhelmsson, L. M.; Lincoln, P.; Brown, T.; Norden, B. Nanofabrication Yields. Hybridization and Click-Fixation of Polycyclic DNA Nanoassemblies. ACS Nano 2011, 5, 7565-7575.

45. Bringer, M. R.; Gerdts, C. J.; Song, H.; Tice, J. D.; Ismagilov, R. F. Microfluidic Systems for Chemical Kinetics that Rely on Chaotic Mixing in Droplets. Philos. Trans. R. Soc., A 2004, 362, 1087-1104.

46. Ho, Y. P.; Grigsby, C. L.; Zhao, F.; Leong, K. W. Tuning Physical Properties of Nanocomplexes Through MicrofluidicsAssisted Confinement. Nano Lett. 2011, 11, 2178-2182.

47. Thomas, P.; Smart, T. G. HEK293 Cell Line: a Vehicle for the Expression of Recombinant proteins. J. Pharmacol. Toxicol. Methods 2005, 51, 187-200.

48. Holm, T.; Johansson, H.; Lundberg, P.; Pooga, M.; Lindgren, M.; Langel, U. Studying the Uptake of Cell-Penetrating Peptides. Nat. Protoc. 2006, 1, 1001-1005.

49. Chen, T.; Shukoor, M. I.; Chen, Y.; Yuan, Q.; Zhu, Z.; Zhao, Z.; Gulbakan, B.; Tan, W. Aptamer-Conjugated Nanomaterials for Bioanalysis and Biotechnology Applications. Nanoscale 2011, 3, 546-556.

50. Mao, C.; Sun, W.; Shen, Z.; Seeman, N. C. A Nanomechanical Device Based on the B-Z Transition of DNA. Nature 1999, 397, 144-146.

51. Niemeyer, C. M.; Adler, M. Nanomechanical Devices Based on DNA. Angew. Chem., Int. Ed. Engl. 2002, 41, 3779-3783.

52. Liu, W.; Zhu, H.; Zheng, B.; Cheng, S.; Fu, Y.; Li, W.; Lau, T. C.; Liang, H. Kinetics and Mechanism of G-Quadruplex Formation and Conformational Switch in a G-Quadruplex of PS2.M Induced by $\mathrm{Pb}(2)(+)$. Nucleic Acids Res. 2012, 40, 4229-4236.

53. Neuman, K. C.; Nagy, A. Single-Molecule Force Spectroscopy: Optical Tweezers, Magnetic Tweezers and Atomic Force Microscopy. Nat. Methods 2008, 5, 491-505.

54. Oteri, F.; Falconi, M.; Chillemi, G.; Andersen, F. F.; Oliveira, C. L.; Pedersen, J. S.; Knudsen, B. R.; Desideri, A. Simulative Analysis of a Truncated Octahedral DNA Nano-Cage Family Indicates the Single-Stranded Thymidine Linkers as the Major Player for the Conformational Variability. J Phys. Chem. C 2011, 115, 16819-16827.

55. Falconi, M.; Oteri, F.; Chillemi, G.; Andersen, F. F.; Tordrup, D.; Oliveira, C. L.; Pedersen, J. S.; Knudsen, B. R.; Desideri, A. Deciphering the Structural Properties that Confer Stability to a DNA Nanocage. ACS Nano 2009, 3, 1813-1822.
56. Bernstein, F. C.; Koetzle, T. F.; Williams, G. J.; Meyer, E. F., Jr.; Brice, M. D.; Rodgers, J. R.; Kennard, O.; Shimanouchi, T.; Tasumi, M. The Protein Data Bank: a Computer-Based Archival File for Macromolecular Structures. J. Mol. Biol. 1977, 112, 535-542.

57. Humphrey, W.; Dalke, A.; Schulten, K. VMD: Visual Molecular Dynamics. J. Mol. Graphics Modell. 1996, 14, 33-38.

58. Case, D. A.; Cheatham, T. E., 3rd; Darden, T.; Gohlke, H.; Luo, R.; Merz, K. M., Jr.; Onufriev, A.; Simmerling, C.; Wang, B.; Woods, R. J. The Amber Biomolecular Simulation Programs. J. Comput. Chem. 2005, 26, 1668-1688.

59. Duan, Y.; Wu, C.; Chowdhury, S.; Lee, M. C.; Xiong, G.; Zhang, W.; Yang, R.; Cieplak, P.; Luo, R.; Lee, T.; et al. A Point-Charge Force Field for Molecular Mechanics Simulations of Proteins Based on Condensed-Phase Quantum Mechanical Calculations. J. Comput. Chem. 2003, 24, 19992012.

60. Jorgensen, W.; Chandrasekhar, J.; Madura, J.; Impey, R.; Klein, M. Comparison of Simple Potential Functions for Simulating Liquid Water. J. Chem. Phys. 1983, 79, 926-935.

61. Phillips, J. C.; Braun, R.; Wang, W.; Gumbart, J.; Tajkhorshid, E.; Villa, E.; Chipot, C.; Skeel, R. D.; Kale, L.; Schulten, K. Scalable Molecular Dynamics with NAMD. J. Comput. Chem. 2005, 26, 1781-1802.

62. Darden, T.; York, D.; Pedersen, L. Particle Mesh Ewald-an N.Log(N) Method for Ewald Sums in Large Systems. J. Chem. Phys. 1993, 98, 10089-10092.

63. Brunger, A.; Brooks, C. L.; Karplus, M. Stochastic BoundaryConditions for Molecular-Dynamics Simulations of St2 Water. Chem. Phys. Lett. 1984, 105, 495-500.

64. Feller, S. E.; Zhang, Y. H.; Pastor, R. W.; Brooks, B. R. Constant-Pressure Molecular-Dynamics Simulation-the Langevin Piston Method. J. Chem. Phys. 1995, 103, 46134621.

65. Ryckaert, J. P.; Ciccotti, G.; Berendsen, H. J. C. NumericalIntegration of Cartesian Equations of Motion of a System with Constraints-Molecular-Dynamics of N-Alkanes. J. Comput. Phys. 1977, 23, 327-341.

66. Miyamoto, S.; Kollman, P. A. Settle-an Analytical Version of the Shake and Rattle Algorithm for Rigid Water Models. J. Comput. Chem. 1992, 13, 952-962.

67. Berendsen, H. J. C.; Vanderspoel, D.; Vandrunen, R. Gromacs_a Message-Passing Parallel Molecular-Dynamics Implementation. Comput. Phys. Commun. 1995, 91, 43-56.

68. Hess, B.; Kutzner, C.; van der Spoel, D.; Lindahl, E. GROMACS 4: Algorithms for Highly Efficient, Load-Balanced, and Scalable Molecular Simulation. J. Chem. Theory Comput. 2008, 4, 435-447.

69. Pettersen, E. F.; Goddard, T. D.; Huang, C. C.; Couch, G. S.; Greenblatt, D. M.; Meng, E. C.; Ferrin, T. E. UCSF ChimeraA Visualization System for Exploratory Research and Analysis. J. Comput. Chem. 2004, 25, 1605-1612. 